\title{
CIRCULAÇÃO MAGMÁTICA EM ZONAS DE CISALHAMENTO: OS DIQUES ALCALINOS NEOPROTEROZÓICOS DA ZONA DE CISALHAMENTO DE ITABUNA-ITAJU DO COLÔNIA, SSE DO ESTADO DA BAHIA, BRASIL.
}

\author{
LUIZ CÉSAR CORRÊA GOMES*****,ELSON PAIVA DE OLIVEIRA*' JOHILDO FIGUEIREDO SALOMÃO BARBOSA** \& \\ MARIA ALBA FARIAS TANNER DE OLIVEIRA**
}

\begin{abstract}
MAGMATIC CIRCULATION IN SHEAR ZONES: THE NEOPROTEROZOIC ALKALINE DYKES OF THE ITABUNA-ITAJU DO COLONIA SHEAR ZONE, SSE OF BAHIA STATE, BRAZIL Fluid migration in shear zones is a difficult feature for three-dimensional reconstruction. One of the most complex problem is to find a single area that combines at the same time rheological and structural aspects. In southeastern Bahia State, Brazil, Neoproterozoic alkaline felsic and mafic dykes of the Itabuna-Itaju do Colonia Dyke Province were emplaced along the N45-trending Itabuna-Itaju do Colônia Shear Zone. They offer a rare opportunity to study magmatic circulation coeval to the tectonic activities of a shear zone. Altogether 524 dykes were examined. In 60 of them reliable markers of magmatic flow sense could be found. When the flow Hneations are plotted on a map, tridimensional flow patterns begin to appear. Two patterns can be easily highlighted: (i) a regular straight, parallel or sub-parallel to the main shear zone, with alternating NE and SW flow sense, related to the shear zone tectonic control and (ii) a radial, with divergent magmatic flow sense, indicating that production of the fracture-conduits were controlled by magmatic overpressure. On the basis of the radial and regular straight patterns and magmatic flow trails, it can be suggested: (i) locations of the alkaline felsic and mafic sources in subsurface and within the shear zone and (ii) explanations for felsic and mafic alkaline magma mixing phenomena observed on a regional scale.
\end{abstract}

Keywords: Shear zones, Magmatic flow, Alkaline rocks, Neoproterozoic.

RESUMO A migração de fluidos dentro de uma zona crustal cisalhada é um elemento de difícil visualização tridimensional, principalmente por que não é fácil encontrar um local adequado onde possa ser observada uma boa associação entre os aspectos reológicos e estruturais e encontrado este local, torna-se agora complicado determinar espacialmente os sentidos de migração dos fluidos. Uma oportunidade rara que permite combinar estes aspectos aparece em uma área que apresenta diques alcalinos félsicos e máficos neoproterozóicos que se alojam segundo o controle de uma zona de cisalhamento, no sudeste do Estado da Bahia, Brasil. Os diques da Província de Itabuna-Itaju do Colônia se colocam segundo os planos rupturais produzidos pela Zona de Cisalhamento de Itabuna-Itaju do Colônia, orientada N45 ${ }^{\circ}$, permitindo que sejam analisados fenômenos de circulação magmática coevos com as atividades tectônicas de uma zona de cisalhamento. Ao todo, 524 diques foram examinados, sendo que em 60 deles puderam ser encontrados marcadores confiáveis do sentido de fluxo magmático. Quando as lineações de fluxo foram lançadas em mapa, padrões tridimensionais de fluxo apareceram, sendo que dois tipos distintos podem ser separados: (i) um padrão retilíneo, paralelo a sub-paralelo à zona de cisalhamento, com alternância de sentidos para NE e SW, relacionado ao controle tectônico da zona de cisalhamento, e (ii) um padrão radial, com sentidos de fluxo centro-divergente, indicando que o fraturamento magmático foi o responsável pela produção das fraturas-conduto. Com base nas trajetórias de fluxo nos padrões radiais e retilíneos, puderam ser sugeridas: (i) as localizações em subsuperfície de fontes magmáticas alcalinas félsicas e máficas, dentro da zona de cisalhamento, e (ii) explicações para o posicionamento de fenômenos de mistura magmática de magmas alcalinos félsicos e máficos observados em escala regional.

Palavras-chave: Zonas de Cisalhamento, Fluxo Magmático, Rochas Alcalinas, Neoproterozóico.

INTRODUÇÃO O estudo dos mecanismos de construção de zonas de cisalhamento tem sido impulsionado principalmente pelo interesse econômico que existe nas relações entre a tectônica e as mineralizações associadas (p.ex: Au em veios de quartzo e pegmatitos com minerais ricos em elementos do grupo dos terras raras).

Além disto, o controle de dinâmica reológica dentro de zonas de cisalhamento pode ser de crucial importância no entendimento de mecanismos de colocação de corpos tabulares e, de um modo geral, da circulação de fluidos na litosfera (Halls 1982, Halls \& Fahig 1987, Parker et al. 1990, Baer \& Heimann 1995).

Uma das vantagens do estudo de rochas filonianas em zonas de cisalhamento está no fato de que as mesmas permitem uma melhor visualização das rupturas formadas durante o tectonismo, possibilitando uma investigação mais apurada dos padrões de fluxo dentro das fraturas-conduto produzidas.

Este tipo de situação pode ser encontrada no sudeste do Estado da Bahia, dentro do Cinturão Granulítico de Itabuna, mais precisamente na região compreendida entre as cidades de Uruçuca e Potiraguá (Fig.l), onde aparecem dois elementos geológicos neoproterozóicos de grande expressão regional: (i) a Zona de Cisalhamento Itabuna-Itaju do Colônia (ZCIIC), de características deformacionais frágeis a frágildúcteis, com último movimento registrado transcorrente dextral, orientada $\mathrm{N}^{\circ} 5^{\circ}$ e afetando uma área em torno de $4500 \mathrm{~km}^{2}$ e (ii) a Província de diques de Itabuna-Itaju do Colônia (PUC), uma das maiores concentrações conhecidas de rochas filonianas félsicas e máficas alcalinas no Estado e que se encontra praticamente toda confinada à zona de cisalhamento.

Tanto a ZCIIC quanto a PUC possuem íntimas relações genéticotemporais com as suítes alcalinas de Itabuna, Itaju do Colônia e Potiraguá, pertencentes à Província Alcalina do Sul da Bahia.

GEOLOGIA REGIONAL Pelo menos três principais eventos geodinâmicos podem ser evidenciados na área de influência da ZCIIC. O primeiro no Paleoproterozóico, durante o ciclo Transamazônico, com geração e deformação de rochas de alto grau metamórfico. 0 segundo, aproximadamente na transição Meso-Neoproterozóico, co- incidindo com um domeamento litosférico associado a uma pluma mantélica e provável deposição dos sedimentos do Grupo Rio Pardo. O terceiro durante o Neoproterozóico, compreendendo a geração de zonas de cisalhamento reversas e transcorrentes e intrusão dos sienitos da Província Alcalina do Sul da Bahia

As principais encaixantes dos diques alcalinos são granulitos máficos a intermediários do Cinturão Itabuna, de idade paleoproterozóica, que misturam características geoquímicas de três suítes distintas, posicionadas de E para W: tholeiítica, calcioalcalina e shoshonítica (Barbosa 1986, Figueiredo \& Barbosa 1993, Barbosa 1996).

Pelo menos duas fases de deformação modelaram estes litotipos (Barbosa 1996, Sabaté 1996): (i) a primeira correspondente a cisalhamentos reversos, aproximadamente N-S e inclinados para $\mathrm{E}$, que jogaram fatias do embasamento de E para W, (ii) a segunda fase marcada por "transpurrões" sinistrais, como reflexo de uma compressão regional submeridiana e que registrou a sua presença na forma de lineações penetrativas sub-horizontais, que obliteraram quase totalmente as lineações da fase anterior. Ambas as fases ocorreram em níveis crustais profundos, compatíveis com a fácies granulito. Como resultado desta intensa deformação, praticamente todo o Cinturão Itabuna apresenta foliações orientadas próximas a N10 e com mergulho variável para $\mathrm{E}$.

Após a evolução paleoproterozóica, estes terrenos granulíticos passaram por um período de tranquilidade durante o Mesoproterozóico, só voltando a ser perturbados tectonicamente durante a transição Meso-Neoproterozóico, pela atuação de uma pluma mantélica que teve como principal consequência um domeamento litosférico de eixo maior N-S com, no mínimo, $1200 \mathrm{~km}$ de comprimento (Corrêa Gomes et al. 1988, Corrêa Gomes 1992), que propiciou distensão crustal suficiente para o alojamento de um enxame de diques tholeíiticos, notadamente nas regiões de Ilhéus e Olivença, cujas idades ficam em torno de 1. 1-1.0 Ga (Renné et al. 1990). Além disto, pode ter ocorrido nesta época a formação e deformação dos litotipos da bacia sedimentar do Rio Pardo (Pedreira 1979, Karmann 1987)

$\mathrm{O}$ terceiro evento geodinâmico principal ocorreu durante o Ciclo Brasiliano, com: (i) a formação e reativação das Zonas de Cisalhamen-

* Instituto de Geociências, Universidade Estadual de Campinas, Caixa Postal- 6152, CEP- 13.083-970, FAX- (019) 239-1562, Campinas, Brasil. e-mail:gomes@ige.unicamp.br

** Instituto de Geocências, Universidade Federal da Bahia, 40.170-290, PABX (071) 247-2566, Salvador, Brasil.

*** Departamento de Geosrafia. Universidade Católica do Salvador. Cammus da Federação, tel: (071) 247-1233. ramal 18.40.000-000. Salvador, Brasil 


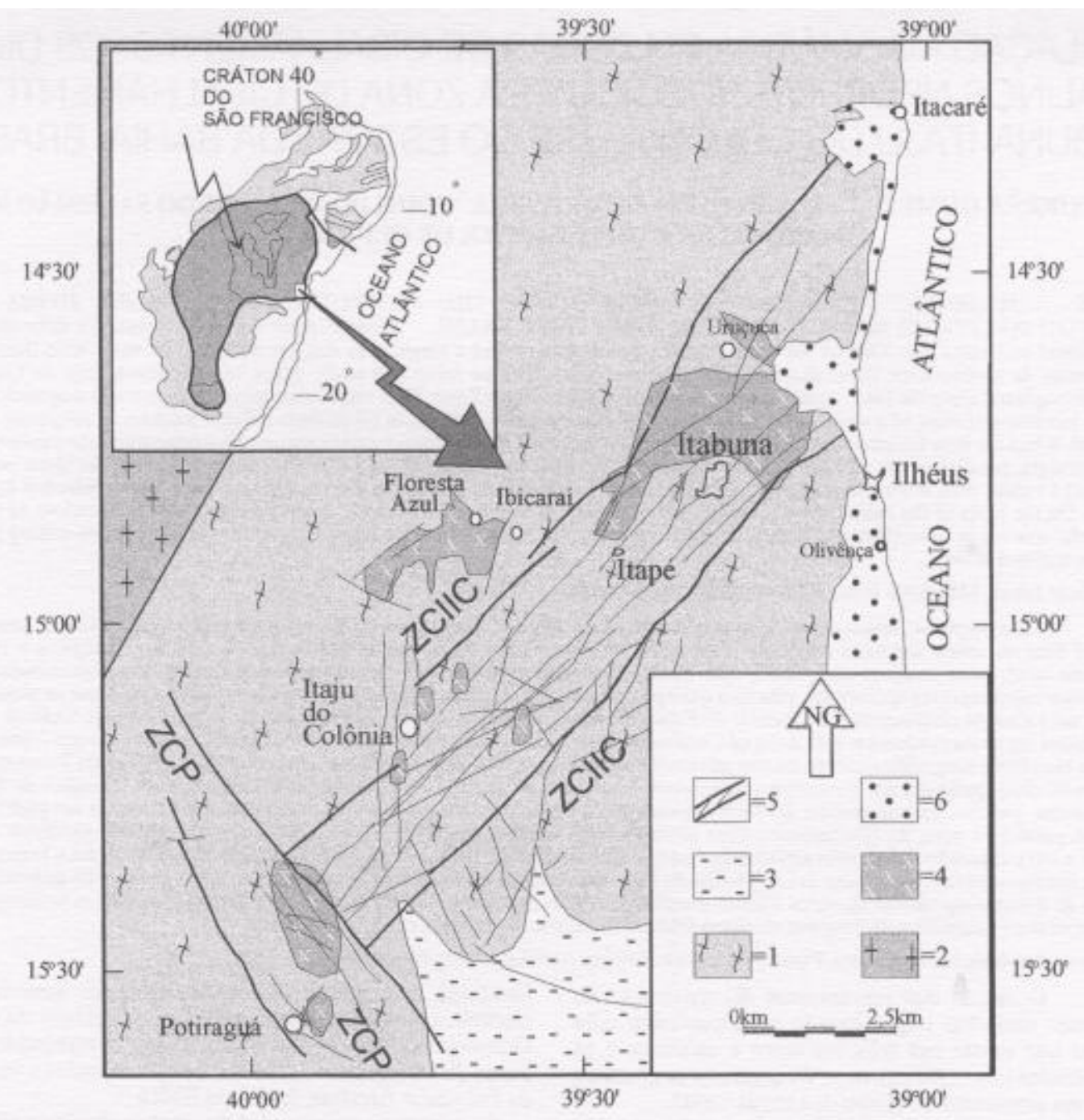

Figura l- Localização da área no Estado da Bahia, Brasil, e das zonas de cisalhamento de Itabuna-Itaju do Colônia (ZCIIC) e de Potiragua (ZCP), no contexto geológico regional. Os diques alcalinos neoproterozóicos se encontram praticamente confinados na ZCIIC e apresentam como encaixantes granulitos paleoproterozóicos do Cinturão Itabuna e, localmente, sienitos neoproterozóicos da Suite Alcalina do Sul da Bahia (modificado de Barbosa \& Domingues, 1996). 1 = Cinturão Granulítico de Itabuna; 2 = Bloco Granulítico de Jequié, ambos paleoproterozóicos; 3 = Metassedimentos Meso(?)-Neoproterozóicos do Grupo Rio Pardo; 4 - Sienitos Neoproterozóicos, 5 = Lineamentos estruturais ligados às ZCIIC e ZCP e 6 = Coberturas fanerozóicas.

tos de Potiragua, com cisalhamentos reversos-dextrais seguidos de transcorrentes sinistrais, e de Itabuna-Itaju do Colônia, iniciada com uma transcorrência sinistral e finalizada por outra dextral (Corrêa Gomes et al. 1996), (ii) colocação e deformação de vários plútons alcalinos da Província Alcalina do Sul da Bahia (Silva Filho et al 1974) e (iii) a movimentação da Faixa Marginal de dobramentos brasilianos Araçuaí (Brito Neves et al. 1980).

\section{A ZONA DE CISALHAMENTO DE ITABUNA-ITAJU DO} COLONIA A Zona de Cisalhamento de Itabuna-Itaju do Colônia ZCIIC, possui uma área de influência de aproximadamente $4500 \mathrm{~km}^{2}$, cujo eixo maior com $150 \mathrm{~km}$ se prolonga segundo uma direção $\mathrm{N} 45^{\circ}$ bem marcada (Fig.2). A abundância de zonas de fraturamento do tipo Riedel e anti-Riedel, o estilo rúptil da deformação associada e a atuação apenas localizada de deformação dúctil, conferem à ZCIIC um caráter predominantemente frágil à frágil-dúctil, característica de zonas crustais rasas. O seu último movimento registrado corresponde a uma transcorrência dextral (Arcanjo 1993). Mais recentemente Corrêa Gomes et al. (1998) sugeriram a existência de uma primeira fase sinistral transpressiva, que foi seguida por uma segunda fase dextral transtensiva, tomando como base o estudo de marcadores cinemáticos (e.g.degraus e estrias de deslizamento) encontrados em planos de fraturas e em diques locais que apresentam, em vários locais, evidências de inversão de movimento.

$\mathrm{O}$ cisalhamento rúptil afetou indistintamente todo o conjunto de litotipos existentes na região, desde os terrenos granulíticos paleoproterozóicos do Cinturão Itabuna até as rochas alcalinas neoproterozói- cas das Suítes de Itabuna, Itaju do Colônia e Potiragua (Fujimori 1967, Barbosa de Deus et al. 1976, Oliveira et al. 1980. Lima et al. 1981, Arcanjo \& Oliveira 1991, Arcanjo 1993, Martins \& Santos 1993, Conceicão \& Otero 1996), datadas entre 0,68 Ga e 0,57 Ga (Lima et al. 1981, Teixeira et al. 1997).

Dentro da ZCIIC vários conjuntos de rochas tabulares podem ser individualizados (Corrêa Gomes et al 1996): i) diques metamórficos anfibolitizados da Província Metamórfíca, com idades mínimas prováveis paleoproterozóicas, subconcordantes a totalmente discordantes da foliação regional $\mathrm{N} 10^{\circ}$; ii) diques máficos tholeí́ticos da Província Litorânea, com idades próximas a $1,0 \mathrm{Ga}$ e com orientações principais $\mathrm{N} 90^{\circ}$ e $\mathrm{N} 120^{\circ}$ e iii) diques máficos e félsicos de tendência alcalina da Província Itabuna-Itaju do Colônia, de prováveis idades neoproterozóicas, orientados principalmente segundo planos $\mathrm{N} 45^{\circ}$, $\mathrm{N} 65^{\circ}, \mathrm{N} 20^{\circ}$ e $\mathrm{N} 00^{\circ}$.

No campo a separação destes conjuntos filonianos foi facilitada pelas suas diferentes características metamórficas e deformacionais, sendo que os diques da Província Metamórfíca, mais antigos, foram metamorfisados na fácies anfibolito, o que não acontece com os diques das duas outras províncias, e os diques tholeíiticos da Província Litorânea estão normalmente mais cisalhados do que os diques alcalinos da Província Itabuna-Itaju do Colônia, mais novos.

O MAGMATISMO FISSURAL ALCALINO DA PROVÍNCIA ITABUNA-ITAJU DO COLÔNIA O magmatismo fissural relacionado à Província Itabuna-Itaju do Colônia- PUC (Fig.3) é representado por várias centenas de diques de composição alcalina, que se 
encontram situados dentro na zona de ocorrência da Suite Alcalina do Sul do Estado da Bahia (Lima et al. 1981, Arcanjo \& Oliveira 1991, Araújo et al. 1992, Arcanjo et al. 1992, Arcanjo 1993, Tanner de Oliveira 1996). Localmente apresentam uma maior concentração de corpos, notadamente nas porções mais centrais da zona de cisalhamento, como no caso da cidade de Itapé a sudoeste de Itabuna.

Os marcadores cinemáticos observados nos diques (e.g. estrias, degraus, deslocamento de marcadores planares externos), as relações de corte entre os conjuntos filonianos alcalinos e os posicionamentos dos planos de colocação dos conjuntos félsico e máfico tornam possíveis algumas indicações importantes (Corrêa Gomes et al. 1998). Para os diques félsicos: (i) eles são ligeiramente mais antigos que os máficos, (ii) eles penetraram na ZCIIC, no máximo, em uma situação tardi-tectônica da fase sinistral transpressiva, (iii) eles ocuparam principalmente fraturas T, R e R' produzidas nesta fase e (iv) eles apresentam marcas da deformação sinistral, de modo menos marcante, e da dextral. Para os diques máficos: (i) eles foram formados durante todo o período de atividades de fase dextral transtensiva, (ii) eles ocupam fraturas tanto da fase sinistral quanto da dextral e (iii) eles são afetados apenas pela tectônica dextral.

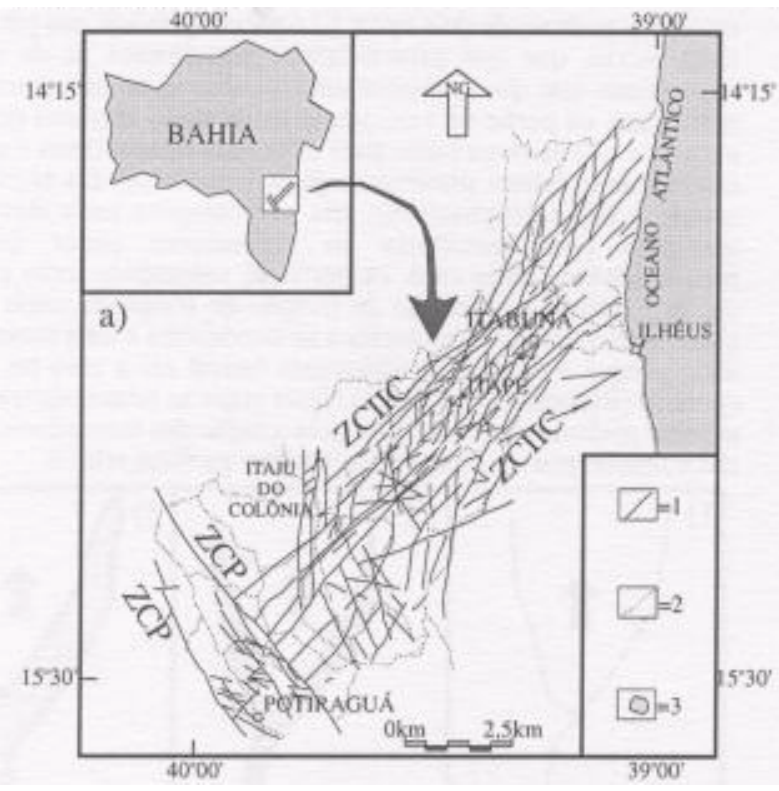

Apesar de ainda não existirem datações radiométricas precisas sobre estes diques alguns dados, extraídos de outros trabalhos realizados na região, permitem inferir uma ideia aproximada das suas idades (Arcanjo \& Oliveira 1991, Araújo et al 1992, Arcanjo 1993, Corrêa Gomes et al. 1993, Corrêa Gomes et al. 1996, Teixeira et al 1997): (i) a ZCIIC provavelmente controlou a colocação do corpo sienítico de Itabuna; (ii) os diques alcalinos cortam e são cortados pelo sienito de Itabuna; (iii) os diques alcalinos apresentam semelhanças mineraloquímicas com os corpos sieníticos da Suíte Alcalina do Sul da Bahia; (iv) os diques alcalinos tiveram suas colocações controladas pela ZCIIC e (v) os diques alcalinos, por vezes, carregam porções de massas sieníticas, semelhantes ao sienito de Itabuna, algumas delas em estágio ainda viscoso, sugerindo que o corpo sienítico ainda não havia sido totalmente solidificado durante a penetração dos corpos filonianos.

De modo combinado, estes fatos apontam para uma contemporaneidade entre a zona de cisalhamento, os corpos sieníticos e os diques alcalinos. Sendo assim as idades entre $680 \mathrm{Ma}$ e $570 \mathrm{Ma}$ obtidas por Lima et al. (1981),Rb-Sr; e Teixeira et al.(1997),U-Pb,para os plútons da Província Alcalina do Sul da Bahia, devem corresponder aproxi-

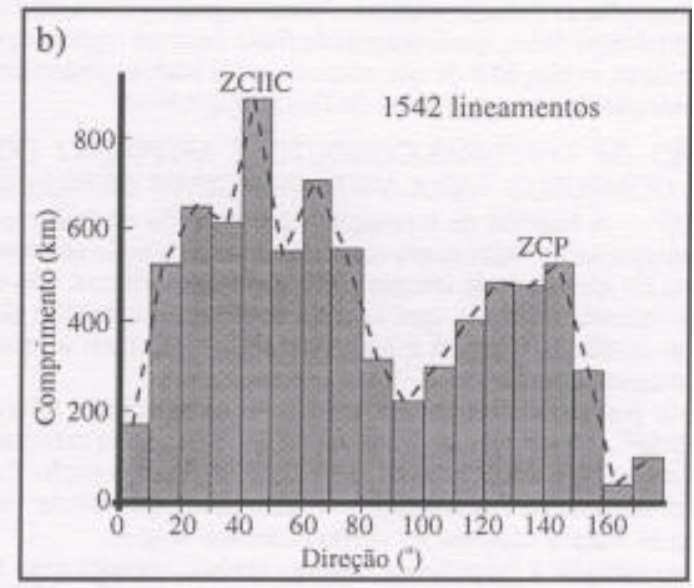

Figura 2 - Principais lineamentos estruturais da zonas de cisalhamento de Itabuna-Itaju do Colônia-ZCIIC e de Potiraguá-ZCP (a) e histograma de comprimento das direções dos lineamentos estruturais da ZCIIC e da ZCP (b), 1 = Lineamentos estruturais; 2 = Estradas; 3 - Cidades.
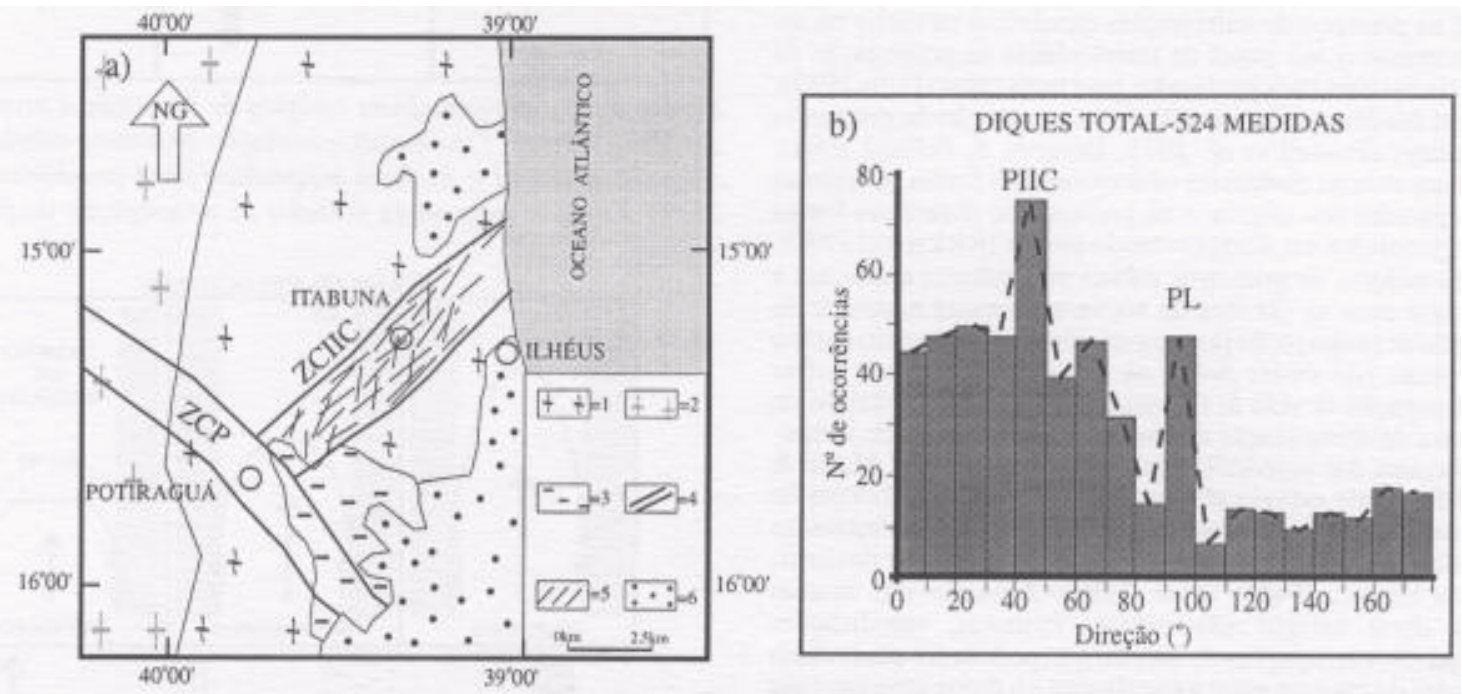

Figura 3 - Representação esquemática dos planos de colocação dos diques alcalinos neoproterozóicos na zona de cisalhamento de Itabuna-Itaju do Colônia - ZCIIC (a) e histograma de frequência de ocorrência de direção para os diques na área de influência da ZCIIC (b), notar a presença da concentração $\mathrm{N}^{\circ} 0^{\circ}$, relacionada à Província Litorânea (PL). J = Bloco granulítico de Jequié, paleoproterozóico, $2=$ Cinturão granulítico de Itabuna, paleoproterozóico, 3 = Grupo Rio Pardo, meso(?)-neoproterozóico, 4 = Zonas de cisalhamento de Itabuna-Itaju do Colonia (ZCIIC) e Potiraguá (ZCP), 5 = Diques alcalinos da Província Itabuna-Itaju do Colônia e 6 - Cobertura sedimentar fanerozóica. 
madamente às idades dos diques alcalinos e provavelmente também aos picos de atividade tectônica da ZCIIC.

Tipologia dos diques alcalinos Com base em observações de campo podem ser separados dois grupos de diques alcalinos na Província de Itabuna-Itaju do Colônia- PIIC: i) diques félsicos traquíticos, com presença de agregados de fenocristais de K-feldspato e plagioclásio triangulares e losangulares, anfibólios e piroxênios, normalmente envolvidos por uma matriz feldspática extremamente fina e escura e ii) diques máficos, mais abundantes e ligeiramente mais jovens que os diques félsicos, predominantemente faneríticos e porfíricos, aparecendo, com menor frequência, na forma de diques contendo concentrações de massas sieníticas, platiformes a arredondadas, nas suas porções centrais, e de vênulas com espessura máxima de $2 \mathrm{~cm}$.

As observações macroscópicas são reforçadas pelas características mineraloquímicas dos diques da PIIC, que foram classificados nos seguintes tipos: (i) diques félsicos de filiação alcalina, sub-divididos em quartzo-traquitos, traquitos e fonólitos e (ii) diques máficos de filiação alcalina, sub-divididos em basanitos, alcali-basaltos, hawaiitos e mugearitos.

Se por um lado começam a ser esboçadas a distribuição geográfica, a tipologia, as relações temporais com as fases tectônicas da ZCIIC e as idades dos diques alcalinos da Província Filoniana de Itabuna-Itaju do Colônia, por outro lado os padrões de circulação magmática dentro da zona de cisalhamento que os hospeda permanecem ainda um tanto obscuros. Isto tornou necessária a adoção de uma metodologia específica (cf. Corrêa Gomes 1992) que permitisse o entendimento de como foram formadas as fraturas-conduto, como se propagaram, como o magma viajou dentro delas, quais marcas de fluxo ficaram registradas em cada etapa desta evolução e de que maneira estas marcas poderiam conduzir a obtenção de um vetor local de fluxo magmático.

PROPAGACÃO DE FRATURAS-CONDUTO E MIGRACÃO DO MAGMA EM CONDUTOS TABULARES -PRINCIPAIS ESTÁGIOS REOLÓGICOS A história de formação e propagação de fraturasconduto e da migração do magma em condutos tabulares pode ser bem mais complexa do que se pode imaginar em modelos teóricos. Ela é composta por inúmeros passos que começam com a nucleação da fratura que vai receber o magma e só tende a terminar com a total solidificação magmática.

Esta história pode ser dividida em três estágios principais (Baer 1995): (i) nucleação e formação da fratura-conduto ou concha externa; (ii) penetração dos primeiros pulsos magmáticos e propagação da ponta do filão ou concha intermediária e (iii) circulação plena do magma dentro da fratura conduto ou corpo filoniano (Fig.4).

No primeiro estágio, a geração da fratura-conduto começa com a formação localizada de um núcleo (ou ponto) de tensão (Reches 1978, 1988) que contrapõe a tensão externa local à pressão magmática (Segall 1984). O resultado deste jogo vai determinar com qual força e em qual direção a fratura vai se propagar. Outro importante fator de influência está na presença de anisotropias mecânicas na rocha encaixante, que aumentam o seu papel de interferência na propagação da fratura, de níveis crustais mais profundos para mais rasos (Halls 1982). Este estágio é de fundamental importância na construção da geometria do corpo filoniano (Pollard et al. 1975, Delaney \& Pollard 1981). Algumas das suas marcas podem ser observadas sob forma de fraturas plumosas, nas paredes dos diques, e na presença de diques em forma de degraus, segmentados ou ainda portando pontes (Rickwood 1990).

No segundo estágio, os primeiros pulsos magmáticos começam a entrar em contato com as paredes da rocha-encaixante e, apesar de terem um sentido de propagação já razoavelmente definido pelo campo de tensão de ponta (tip stress field), os diques podem ainda sofrer desvios de propagação devido à: (i) variações locais no conteúdo de voláteis e na taxa de cristalização do magma e (ii) presença de irregularidades no formato das paredes (Segall 1984, Rubin 1995, Morin \& Corriveau 1996). Neste estágio são formadas as primeiras bordas de resfriamento que, a depender das suas espessuras, podem ser destruídas total ou parcialmente pelos próximos pulsos do magma, por devitrificação e erosão térmica (Fabre et al. 1989). Algumas das marcas características deste estágio são estrias, ranhuras, ramificações menores e pequenas corrugações de arrasto que podem ser observadas nas proximidades do contato entre a encaixante e o dique e/ou nas suas margens de resfriamento (Baer \& Reches 1987, Smith 1987, Corrêa Gomes et al 1988, Corrêa Gomes 1992).

O terceiro estágio é o mais rico em feições de fluxo produzidas porque, estabelecida a carga magmática plena, começa a haver uma mudança no seu comportamento reológico, que é controlado, mais uma vez, pela percentagem de voláteis, taxa de solidificação e volume de enclaves (Shaw et al. 1968, Shaw 1969, Johnson \& Pollard 1973, Blanchard et al. 1979, Fernandez 1984, McBirney \& Murase 1984, Nicolas 1992, Morin \& Corriveau 1996, McBirney \& Nicolas 1997). Isto terá reflexos cruciais sobre a viscosidade do magma, nos seus perfis de velocidade de propagação e nas taxas de cisalhamento (shear rate) laterais produzidas (Fig.5).

Existem, neste estágio, três domínios que apresentam um gradativo aumento na viscosidade :

-Domínio I, onde o magma começa com baixa carga de cristais e/ou conteúdo de xenólitos ( $<30 \%$ do volume total). O magma pode apresentar um comportamento de fluido newtoniano, ou seja não apresenta resistência ao escoamento (yield strength). Assim, uma vez iniciada a intenção de movimento, o magma flui naturalmente. A partir daí, o seu perfil de velocidade de propagação vai ser modelado por sua baixa coesão molecular interna. Os perfis de velocidade serão portanto elípticos e alongados e as taxas de cisalhamento decrescem rapidamente das bordas para o centro. Nesta etapa, fenômenos de diferenciação por fluxo, bandamento magmático e algumas acumulações cristalinas dominam o quadro de feições reológicas produzidas;

-Domínio II, onde com o aumento da taxa de solidificação e/ou no conteúdo de xenólitos (30\%-60\% do volume total) o comportamento reológico pode ser de dois tipos: (i) o pseudoplástico, nas percentagens mais baixas, que tem características semelhantes ao de um fluido newtoniano mas que apresenta uma resistência ao escoamento maior; neste caso, os perfis de velocidade ainda serão elípticos porém mais curtos do que os observados para os fluidos newtonianos e as taxas de cisalhamento lateral diminuirão mais lentamente das bordas para o centro, e (ii) o binghamiano, nas percentagens mais elevadas, que apresenta uma resistência ao escoamento maior que o do pseudoplástico; neste caso, os perfis de velocidade serão ainda mais curtos e haverá a formação do tampão de Bingham, onde toda uma parte central da frente magmática se movimenta a uma mesma velocidade porque a taxa de cisalhamento lateral cai a zero no centro do conduto (Blanchard et al. 1979).Nesta etapa as principais tramas magmáticas poderão ser produzidas pela rotação dos marcadores cinemáticos e fenômenos de fluxo intracristalino ganham relevo.

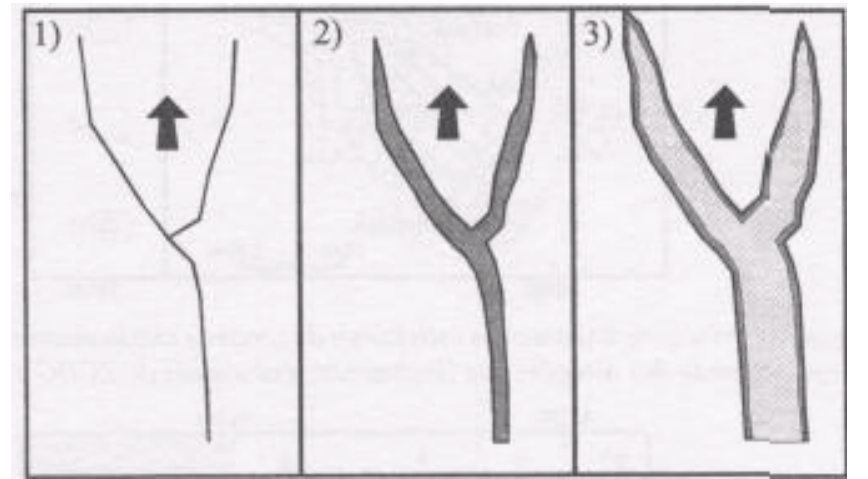

Figura 4 - Os três principais estágios deformação e propagação de um corpo tabular: l) formação e evolução da fratura-conduto, 2) fluxo magmático inicial e 3) fluxo magmático final (modificado de Baer 1995). As setas indicam os sentidos de propagação dafratura e do magma.

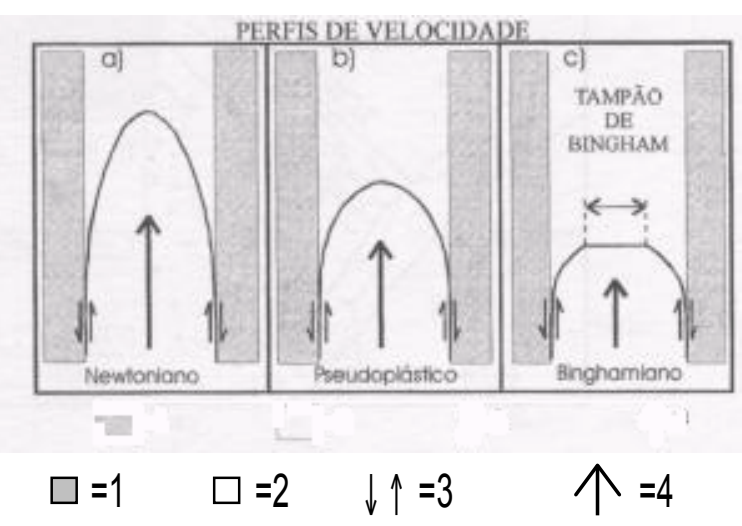

Figura 5 - Perfis de velocidade de fluxo para fluidos ideais: a) newtonianos, b) pseudoplásticos e c) binghamianos, com formação do tampão de Bingham (modificado de Blanchard et al. 1979). $l=$ Rocha encaixante; 2 = Corpo tabular; 3 = Cisalhamento lateral e $4=$ Sentido do fluxo magmático. 
-Domínio III onde, para valores de solidificação e/ou presença de xenólitos $60 \%$ do volume total, o comportamento magmato-rígido prevalece.

Algumas feições produzidas nestes três domínios do terceiro estágio são: alinhamento de cristais, cristais imbricados, geração de cristais com geometrias a (sigma) e 5 (delta), fraturamento escalonado de cristais, efeitos de bloqueio entre partículas de maior e menor tamanho, foliações S-C laterais, rotação de xenólitos e autólitos, fraturas de Riedel em bordas de resfriamento, entre várias outras (para maiores detalhes ver Elston \& Smith 1970, Smith 1987, Corrêa Gomes et al. 1988, Doblas et al. 1988, Rickwood 1990, Corrêa Gomes 1992, Philpotts \& Asher 1994, Baer 1995, Morin \& Corriveau 1996).

MARCADORES DE FLUXO EM CORPOS TABULARES. MECANISMO DE GERAÇÃO E COMO DEDUZIR A LINHA PRINCIPAL DE FLUXO O mecanismo gerador das principais feições de fluxo em diques é a diferença na taxa de cisalhamento entre as bordas e o centro do corpo. As velocidades menores das bordas e maiores no centro tendem a fazer os marcadores cinemáticos girar e ocupar posições de menor resistência ao fluxo. Ao mesmo tempo, com o aumento da taxa de solidificação do magma, o aumento da viscosidade acentua a dificuldade de rotação desses marcadores. O que ocorre então é uma disputa entre o fluxo, que tende a movimentar os objetos presentes, e o aumento da viscosidade, que trabalha a favor da imobilização dos marcadores.

E é exatamente este procedimento que vai facilitar a obtenção da linha principal de propagação do magma, que pode ser obtida por geometria simples ou pela utilização de redes estereográficas.

Para simplificar a explicação da sistemática metodológica todas as informações que virão a seguir, estarão relacionadas a um dique vertical com um plano de simetria vertical (PSV), paralelo ao seu comprimento maior e localizado no centro do corpo filoniano (Fig.6.la). Este dique não deverá apresentar grandes irregularidades em suas paredes de contato, variações abruptas nas suas taxas de solidificação e deverá ainda estar submetido a uma tensão externa próxima a zero. Neste caso, os marcadores de fluxo vão tender a se posicionar nas bordas de modo simétrico em relação ao PSV, porque as taxas de cisalhamento laterais serão semelhantes (Fig.6.lb).
Com isto dois tipos de marcadores podem ser observados (Figs.6.2,3), tomando como base apenas os seus posicionamentos em relação ao vetor de fluxo local:

(i) marcadores posicionados em alto ângulo com relação ao vetor de fluxo magmático, representados por aqueles que apresentam um ângulo maior que $90^{\circ} \mathrm{com}$ as paredes do conduto e que, comparadas as suas posições nas laterais do dique, "apontam" a favor do sentido do fluxo (e.g. cristais imbricados, planos axiais de dobras de arrasto e fraturas tipo-P) e, marcadores posicionados em baixo ângulo com relação ao vetor de fluxo magmático, que apresentam um ângulo menor que $90^{\circ} \mathrm{com}$ as paredes do conduto e que "apontam" no sentido contrário ao do fluxo (e.g. fraturas R, R' e T e enclaves em bordas de resfriamento).

É portanto de fundamental importância a identificação do tipo de marcador observado para se obter o real sentido de movimentação magmática em cada caso.

No caso das situações de alto ângulo com o vetor de fluxo (Fig.6.2a), os marcadores lineares (e.g. cristais de feldspato) deverão apontar paro o meio do conduto (Shelley 1985), formando um ângulo interno cuja bissetriz dará a linha principal de fluxo local. Nas situações ideais de simetria, a linha bissetriz do ângulo formado deverá estar contida no plano de simetria do dique (Figs.6.2b,c). No caso dos marcadores planares (e.g. cristais de mica) os planos observados em lados opostos do dique, apontarão também para o centro do corpo porém agora o artifício para se obter a linha principal de fluxo será o de se encontrar a bissetriz do ângulo interno formado, mais a linha de interseção entre os planos laterais. A linha que for ao mesmo tempo ortogonal à interseção e paralela à bissetriz será a linha principal de fluxo magmático (Corrêa Gomes 1992).

No caso das situações de baixo ângulo com o vetor de fluxo (Fig.6.3a), os marcadores lineares e planares deverão apontar para o centro do conduto porém contra o sentido de fluxo, sendo assim o procedimento será o mesmo que o anteriormente mencionado, contudo o sentido obtido deverá ser corrigido em $180^{\circ}$, para obtenção do real sentido de fluxo (Figs.6.3b,c).

É importante lembrar que em situações reais o arranjo dos marcadores internos pode ser perturbado por: (i) ação de uma tensão cisalhante externa, (ii) irregularidades nas paredes do corpo tabular e (iii) turbulências locais no fluxo. Estas interferências podem levar a três resultados: (i) transposição dos marcadores de fluxo e imposição

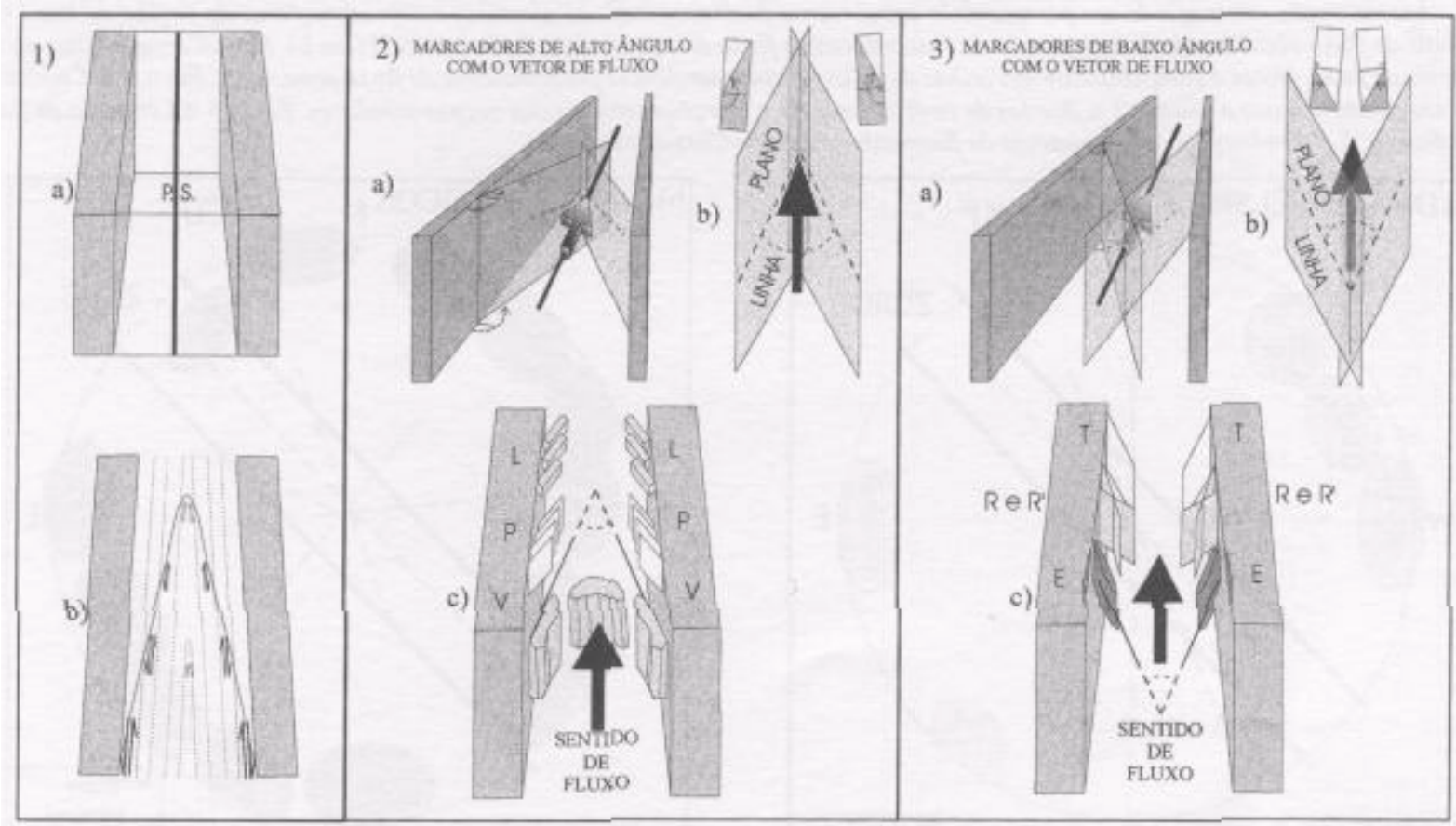

Figura 6 - Em um dique hipotético vertical: 1) visualização do plano de simetria -P.S. (em a) e das diferentes taxas de cisalhamento lateral das bordas para o centro responsáveis pela formação das feições de fluxo (em b); 2) posicionamento dos marcadores de fluxo planares e lineares em situação de alto ângulo com o vetor de fluxo (em a), indicação do vetor principal de fluxo (em b) e apresentação de alguns marcadores característicos, tais como: concentrações viscosas capturadas pelo magma (V) e cristais planares $(P)$ e lineares $(L)$ e 3) posicionamento dos marcadores de fluxo planares e lineares em situação de baixo ângulo com o vetor de fluxo (em a), indicação do vetor principal de fluxo (em b) e apresentação de alguns marcadores característicos, tais como: enclaves em bordas de resfriamento (E), fraturas conjugadas de Riedel ( $R$ e $R^{\prime}$ ) e gashes extensionais (T) (modificado de Corrêa Gomes 1992). 
de uma trama tectônica assimétrica, (ii) apenas rotação do plano de simetria dos marcadores de fluxo e (iii) destruição do plano de simetria sem geração de uma trama tectônica. A intensidade com que estes fatores de interferência vão atuar é que vai ditar a eficiência do método proposto.

Um exemplo do perfil de fluxo construído pela análise dos marcadores reomórficos macroscópicos pode ser observado na região de Itapé (Figs.7a,b). Neste local um par de diques máficos alcalinos, paralelos e concorrentes, apresenta uma enorme quantidade de marcadores planares, representados por porções de massas sieníticas em estados reológicos que vão desde o viscoso ao sólido-rúptil. Estes diques foram submetidos a um cisalhamento sinistral (marcado pelo deslocamento de marcadores planares externos) de fraca intensidade, que não conseguiu modificar o arranjo cinemático imposto pelo magma. Este cisalhamento impôs aos marcadores de fluxo uma ligeira rotação anti-horária.

Áo todo foram obtidas 52 lineações de fluxo, algumas indicando retrofluxo (backflow) e uma fluxo para baixo (downflow), porém a grande maioria aponta para um fluxo preferencial ascendente, de baixo ângulo para norte.

É exatamente esta tendência majoritária de movimentação magmática dentro de um dique, que será chamada a partir de agora de "vetor indicativo de fluxo", que pode ser obtido por um número variável de marcadores reomórficos locais.

PADRÕES DE FLUXO NOS DIQUES ALCALINOS A partir dos vários marcadores reológicos anteriormente observados, foram obtidos 60 vetores indicativos de fluxo nos 524 diques da PUC, que foram plotados em rede estereográfica de igual-área (Fig.8).

Padrões de fluxo em rede estereográfica $O$ posicionamento e os sentidos de fluxo dos diques é uma evidência de que não houve uma clara dominância de um sentido sobre outro. A tendência de fluxo inclinado prevaleceu sobre a de fluxo vertical $(57$ x 3$)$ e a de fluxo para norte se destacou ligeiramente sobre aquela de fluxo para $\operatorname{sul}(27 \times 24)$
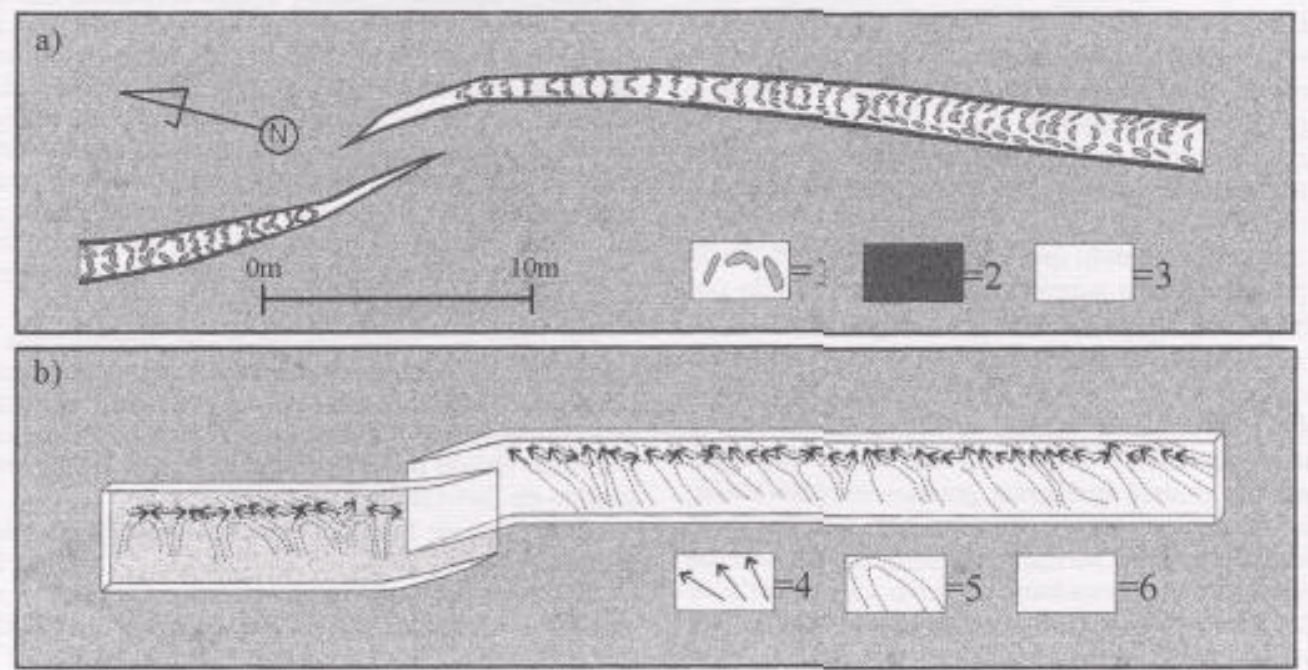

Figura 7 - Apresentação em mapa de um par paralelo concorrente de diques máficos alcalinos neoproterozóicos da região de Itapé (em a) e os seus perfis de fluxo obtidos pela interpretação de marcadores de fluxo do tipo estágio 3 (Baer 1995) (em b). Foram encontrados ao todo 52 vetores locais de fluxo. Notar a complexidade das linhas de fluxo e a clara tendência predominante de fluxo para norte. Em a, $1=$ Concentrações sieníticas em estado viscoso a sólido; 2 = Bordas de resfriamento; $3=$ Porções centrais dos corpos tabulares. Em b, $4=$ Lineação de fluxo com sentido indicado; 5 = Prolongação de trajetória de fluxo inferida e $6=$ Corpos tabulares.
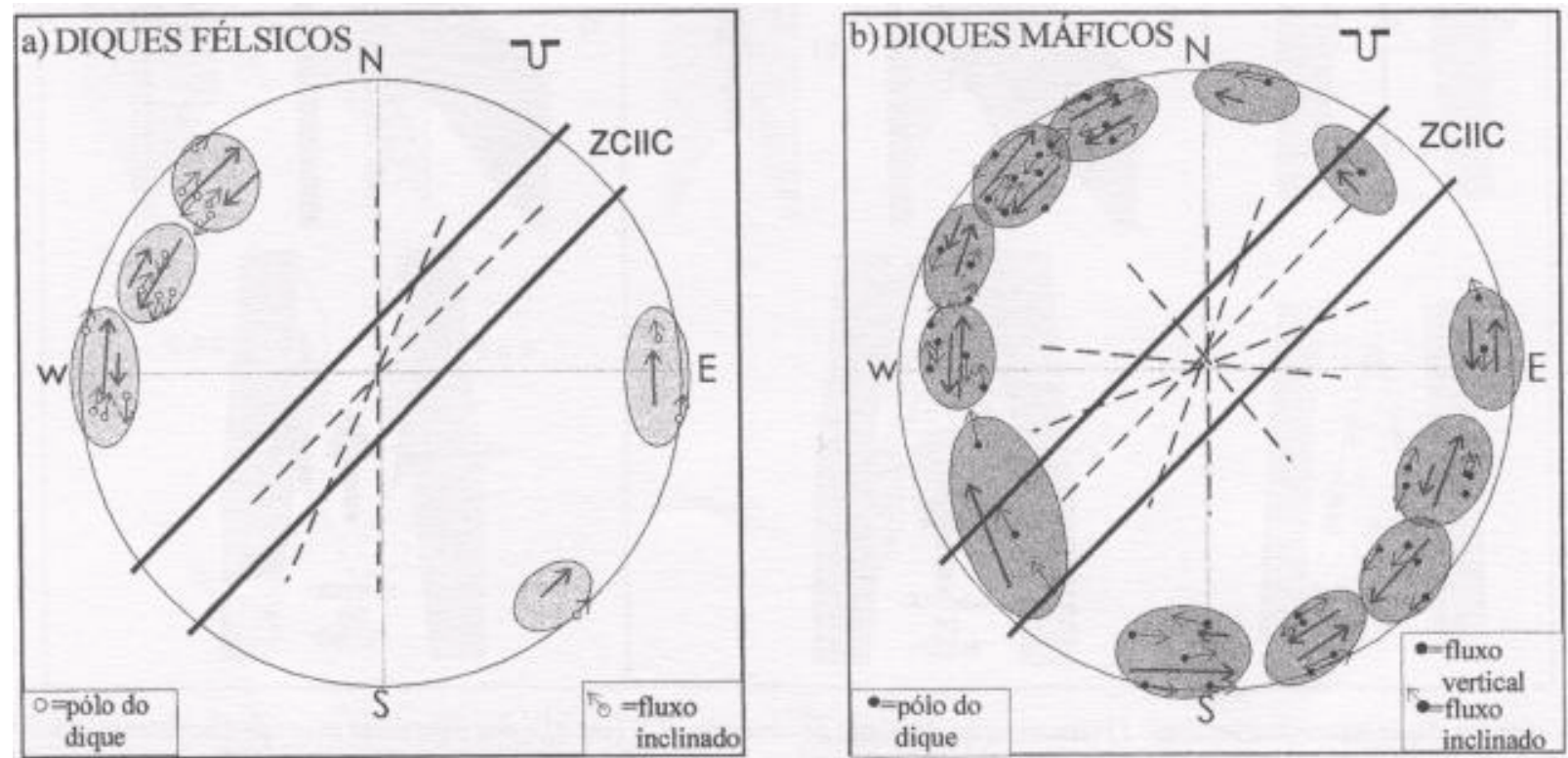

Figura 8 - Marcação dos vetores de tendência de fluxo, paralelos aos strikes, e das áreas de concentração polar, em cinza claro, para diques alcalino félsicos (em a) e, em cinza escuro, para diques máficos (em b). Notar que em algumas orientações planares existe uma tendência de fluxo predominante em um sentido, enquanto que em outras não existe uma dominância clara. As duas linhas grossas paralelas representam a orientação principal da Zona de Cisalhamento de Itabuna-ltaju do Colônia (ZCIIC), as linhas tracejadas as orientações principais dos planos de colocação dos diques alcalinos félsicos e máficos e as setas indicam as tendências de fluxo dos grupos de planos de colocação dos diques. 
Quando são separados os grupos de diques félsicos e máficos, alguns padrões começam a ficar mais claros com alguns setores de orientações apresentando um comportamento mais uniforme (Figs.8a,b). Por exemplo: (i) o magma nos diques félsicos orientados próximos a $\mathrm{N} 00^{\circ}$ fluiu com maior constância para Norte, enquanto que nos diques máficos de semelhante orientação, o fluxo mostrou-se ambíguo, com leve tendência para Norte; (ii) nos diques félsicos $\mathrm{N} 20^{\circ}$ o fluxo para Sudoeste predominou, enquanto que nos máficos o fluxo para Nordeste predominou; (iii) nos diques félsicos $\mathrm{N} 45^{\circ}$ o fluxo para Nordeste foi um pouco mais marcante, enquanto que para os máficos existiu uma maior tendência para Sudoeste; (iv) os diques máficos N65 ${ }^{\circ}$ fluíram tanto para Nordeste quanto para Sudoeste; (v) os diques

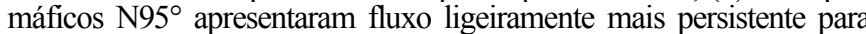
Sudeste e finalmente (vi) os diques máficos $\mathrm{N} 135^{\circ}$ apresentaram marcas de fluxo mais incisivas para Nordeste.

Padrões de fluxo em mapa Quando as projecõos horizontais dos vetores indicativos de fluxo dos diques félsicos e máficos são lançadas em mapa (Fig.9a,b), dois tipos de padrões de migração magmática podem ser observados:

(i) um padrão predominante retilíneo, com diques paralelos e sub-paralelos à ZCIIC, alternando sentidos de fluxo, o que é indicativo de um forte controle da zona de cisalhamento na produção das fraturas- conduto e que as fontes magmáticas alcalinas de onde partiram as injeções, provavelmente, se encontram dentro ou nas proximidades da zona de cisalhamento e,

(ii) um padrão radial, mais localizado, onde o magma em diques de diferentes direções parece estar partindo de uma fonte comum, o que é indicativo de uma forte influência da pressão magmática na construção das fraturas-conduto e reforça a hipótese da localização das fontes de emissão do magma dentro da zona de cisalhamento.

Bons exemplos dos padrões radiais podem ser vistos nas áreas: (i) imediatamente a nordeste de Itabuna, onde o Sienito de Itabuna poderia ser considerado como área fonte, e (ii) a sudoeste e nordeste de Itapé, onde afloram apenas rochas granulíticas, o que reforça a indicação da existência de fontes magmáticas em subsuperfície, pela maneira com que os sentidos de fluxo do magma se distribuem, tanto para os diques félsicos quanto para os diques máficos.

São também dignos de nota (Fig 9c): (i) o alinhamento destas fontes segundo a direção $\mathrm{N}^{\circ} 5^{\circ}$, que corresponde a orientação principal da ZCIIC e (ii) a existência de fenômenos de mistura mecânica de magmas alcalinos máficos e félsicos, exatamente nas áreas de superposição de câmaras magmáticas inferidas pelos padrões radiais.

Todas estas evidências parecem reforçar a ideia de que houve uma combinação de influências mecânicas na formações das fraturas-con-
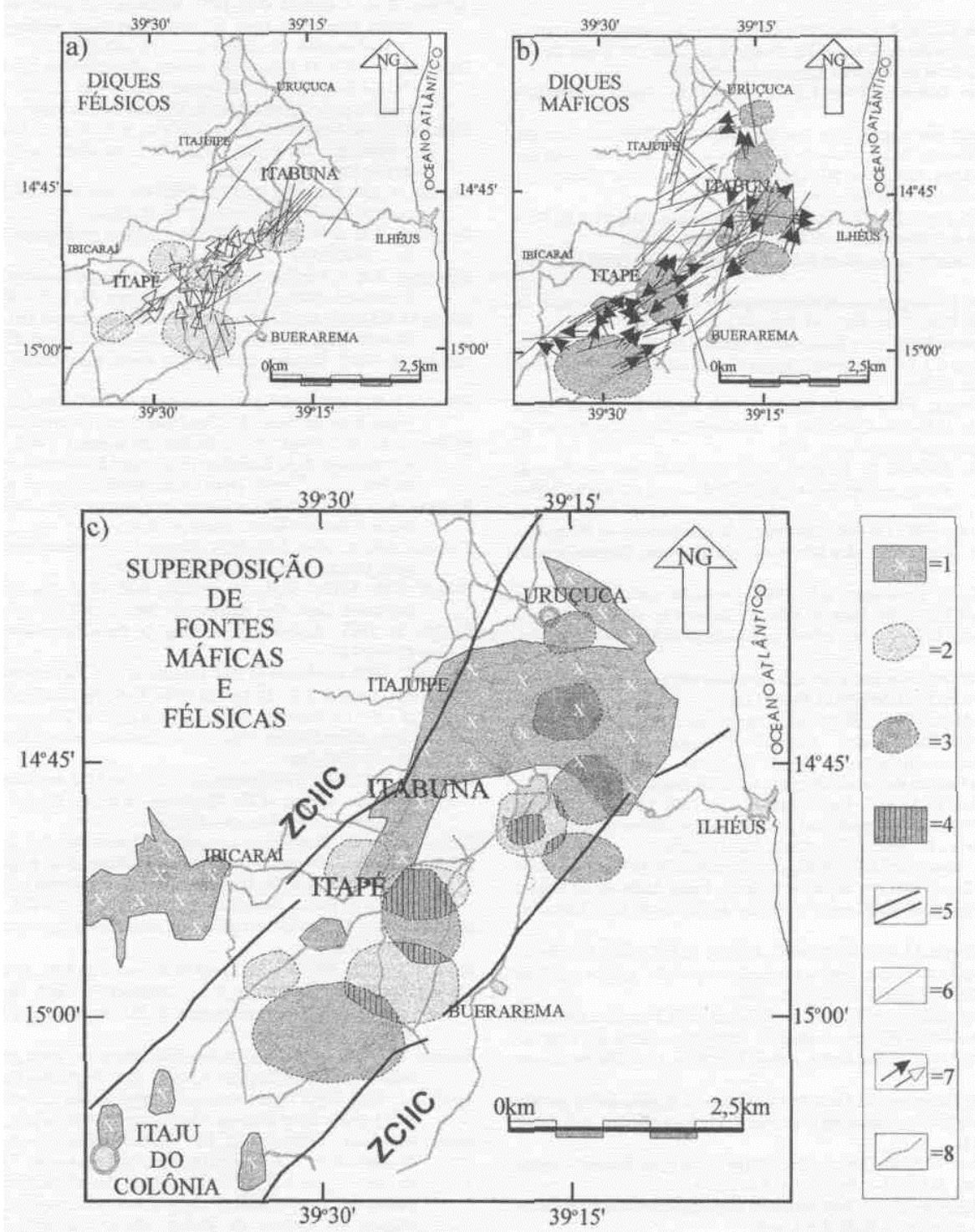

Figura 9 - Principais vetares indicativos de fluxo e localizações de possíveis fontes magmáticas alcalinas félsicas (a) e máficas (b) em subsuperficie, deduzidas pelos padrões radiais encontrados na região de influência da Zona de Cisalhamento de Itabuna-Itaju do ColôniaZCIIC. Em c, podem ser vistas algumas áreas de superposições entre as fontes subsuperficiais, que explicariam fenômenos de mistura entre magmas alcalinos félsicos e máficos encontrados nestes locais, 1 = Sienitos neoproterozóicos; 2 = Possivel fonte magmáticafélsica; 3 = Possível fonte magmática máfica; 4 = Zonas de superposição; 5 = Limites da ZCIIC; $6=$ Direções dos planos de colocação dos diques; $7=$ Sentido de fluxo magmático e $8=$ Estradas. 
duto e dos padrões de migração do magma alcalino na ZCIIC. Esta combinação colocou em jogo a atuação de um campo tensional externo (cisalhamento transcorrente) e a pressão magmática (fraturamento magmático). Quando o campo externo alcançou maior intensidade, os padrões retilíneos e paralelos à ZCIIC dominaram e quando a pressão magmática preponderou, os padrões radiais localmente prevaleceram.

CONCLUSÕES O fluxo do magma na Zona de Cisalhamento de Itabuna-Itaju do Colônia -ZCIIC ocorreu de duas maneiras peculiares : (i) de modo retilíneo e paralelo às fraturas produzidas pela ZCIIC, indicando que a ZCIIC exerceu algum tipo de controle na formação das fraturas-conduto, neste caso a movimentação do magma ocorreu sem que um sentido de fluxo predominasse de modo marcante sobre outro, caracterizando a ZCIIC como uma faixa crustal contendo vários corredores de alternância no sentido de fluxo e indicando a possibilidade de que as fontes dos magmas se encontram próximas e/ou sob a mesma; (ii) de modo radial, com o magma se propagando de modo centro-divergente, o que é indicativo de uma forte influência da pressão magmática na geração das fraturas-conduto.

Deve-se destacar também que estes padrões radiais, associados às trajetórias de fluxo observadas nos diques estudados, serviram para sugerir a localização de corpos ainda não aflorantes, localizados nas proximidades das cidades de Itapé e Itabuna. Além disto, a localização geográfica de fenômenos de mistura mecânica de magmas alcalinos félsicos e máficos pôde ser explicada pela superposição das fontes de emissão dos magma obtidas a partir destes padrões radiais.

Agradecimentos Aos geólogos da CPRM-BA, Nelson Custódio da Silveira Filho, João Batista Arcanjo, Adriano Alberto Marques Martins e Roberto Campeio de Melo, pelas discussões sobre a geologia da área em questão e ao Prof. Dr. Asit Choudhuri do IG-UNICAMP e aos dois revisores anônimos da RBG, pelas valiosas sugestões que enriqueceram o texto. Além disto L.C.C.G. e E.P.O. agradecem a FAPESP pelo apoio financeiro (Processo 96/3582).

\section{Referências}

Araújo, C.B.; Tanner de Oliveira, M.A.F.; Corrêa Gomes, L.C. 1992. Diques alcalinos do sul do estado da Bahia. Uma contribuição aos aspectos: geológico, petrológico e geoquímico. SBG, Congr. Brás. Geol., 37, Simp. Diques Máficos, São Paulo, SP. Boletim de Resumos Expandidos, 500-501

Arcanjo, J.B.A. \& Oliveira, J.E. 1991. Dyke swarms of southeast São Francisco Craton in Itabuna-Itapé area, Bahia, Brasil. In: Inter. Symp. on Mafic Dyke. Excursion Cuide. São Paulo-Brazil, 41-52

Arcanjo, J.B.A.; Oliveira, J.E. de \& Santos, R.A. dos. 1992. Caracterização petrográfica, textural equímica de diques máficos do sul da Bahia. SBG, Congr. Brás. Geol., 37, Simp. Diques Máficos, São Paulo, SP. Boletim de Resumos Expandidos, 498-499.

Arcanjo, J.B.A.1993. Folha de Itabuna. SD.24.Y.B.VI, Estado da Bahia, 1:100.000, DNPM/CPRM, inédito.

Baer, G. 1995. Fracture propagation and magma flow in segmented dykes: Field evidence and fabric analyses, Maktesh Ramon, Israel, In: Baer, G. \& Hei-mann, A. (eds.) Physics and Chemistry of Dykes, selected papers at III Third International Dyke Conference, Jerusalém, Israel, A. A. Balkema, 125-140.

Baer, G. \& Heimann, A. (eds.). 1995. Physics and Chemistry of Dykes. Selected papers at III Third International Dyke Conference, Jerusalém, Israel, A. A. Balkema, 339 p.

Baer, G. \& Reches, Z. 1987. Flow patterns of magma in dykes. Makhtesh Ramon, Israel. Geology, $15,569-572$

Barbosa, J.F.S. 1986. Contribuition lithologique et métamorphique de Ia région granulitique du sudde Bahia, Brésil. Thèse Doct. Univ. Paris VI, Paris-France, tome 86-34. 300p.

Barbosa, J.F.S. 1996.0 Embasamento Arqueano e Protero/óico Inferior do Estado da Bahia. In: Barbosa, J. F. S. \& Dominguez, J. M. L. (coords.). Mapa Geológico do Estado da Bahia. Texto Explicativo., Cap. III, 63-86.

Barbosa, J.F S. \& Dominguez, J.M.L. 1996. Mapa Geológico do Estado da Bahia. Texto Explicativo. Secretaria da Indústria Comércio e Mineração, Superintendência de Geologia e Recursos Minerais.Salvador, Bahia. 400p.

Barbosa de Deus, P.; Rangel, P.A.; Silveira. W. P.; et al. 1976. Projeto Rochas alcalinas de Itarantim- Fase I. Texto e fichas petrográficas. SME/CPM, convénio SME/CBPM. Estado da Bahia, Salvador, $160 \mathrm{p}$

Blanchard, J-P.; Boyer, P.; Gagny. C. 1979. Un Nouveau Critere de sens de Misc en Place dans une Cáisse Filonienne: le "Pincement" des Mineraux aux Epontes. Tectonophysics, 53:1-25.

Brito Neves, B.B.; Cordani, U.C. \& Torquato, J.R.F. 1980. Evolução Geocronológica do Precambriano do Estado da Bahia. In: Inda, H.A.V. \& Duarte,F.B. (eds) Geologia e Recursos Minerais do Estado da Bahia. Sec. Minas do Estado da Bahia.Textos Básicos, 1:1-101.

Conceição, H. \& Otero, O.M.F. 1996. Magmatismo granítico e alcalino no estado da Bahia. Uma epitome do tema. Convénio SICM/SGM/PPPG/UFBA, 133p.

Corrêa Gomes, L.C. 1992. Diques Máficos: Uma Reflexão Teórica sobre o Tema e o seu Uso no Entendimento Prático da Geodinâmica Fissural. Exemplos de Salvador e Ilhéus-Olivença, Zona Costeira Atlântica do Estado da Bahia - Brasil. Instituto de Geociências, Universidade Federal da Bahia, Dissertação de Mestrado, Bahia, 196 p.

Corrêa Gomes, L.C.; Tanner de Oliveira, M.A.F.; Bastos Leal, L.R.B. 1988. Feições estruturais dos diques máficos: Relações entre magmatismo fissural e as condições reológicas do meio. SBG, Cong. Brás. Geol., 35, Belém -PA, Anais, 5:2217-2226

Corrêa Gomes, L.C.; Araújo, C.B.; Tanner de Oliveira, M.A.F.; Cruz, M.J.M. 1993. Mecanismo de intrusão do enxame de diques máficos alcalinos de Itapé. Faixa Atlântica do Craton do São Francisco, Bahia, Brasil. II Simp. sobre o Cráton do São Francisco, Salvador, Bahia., 115-118.

Corrêa Gomes, L.C.; Tanner de Oliveira, M.A.F.; Motta, A.C. \& Cruz, M.J.M. 1996. Províncias dos diques máficos do Estado da Bahia. Mapa, evolução temporal e estágio atual do conhecimento. Convénio SICM/SGM/PPPG/UFBA., 144 p.

Corrêa Gomes'L.C; Oliveira, E.P. de; Barbosa, J.F.S. \& Silva, P.C.F. da 1998.Tectônica associada à colocação de diques alcalinos félsicos e máficos neoproterozóicos na zona de cisalhamento de Itabuna-Itajú do Colônia, Bahia, Brasil. Rev. Brás. Geociências (aceito para publicação)

Delaney, P.T. \& Pollard, D.D. 1981. Deformation of host rocks and flow of magma during growth of minette dykes and breccia-bearing intrusions near Ship Rock, New México. U.S. Geol. Sur. Prof. Paper, 1202, $60 \mathrm{p}$

Doblas, M.; Ubanell, A.G.; Villa Seca, C. 1988. Deformed porphyry dykes in the Spanish Central System. Rend. delia Soe. Ital. di Miner. e Petrol, 43, 2:517-524.

Elston, W.E. \& Smith, E.I. 1970. Determination of flow direction of rhyolitic ash-flow tuffs from fluidal textures. Geol. Soe. Of Amer. Bull., 81:3393-3406.

Fabre, P.; Kast, Y.; Girod, M. 1989. Estimation of flow duration of basaltic magma in fissures. Jour. Volc. And Geoth. Resear., 37:167-186.

Fernandez, A. 1984. Elude théorique et experimentale de Ia fabrique dans les ro- ches magmatiques. Application à l'analyse struturale dês granitoides. Thè-se Doct. Science, Univ. Clemont Ferrand, Clemont Ferrand, France, 239 p.

Figueiredo, M.C.H. \& Barbosa, J.S.F. 1993. Terrenos metamórficos de alto grau do Craton do São Francisco. In: Domingues, J. M. L. \& Misi, A.(eds), O Craton do São Francisco. Reunião Preparatória do II Simp. do Craton do São Francisco, 63-84
Fujimori, S. 1967. Rochas alcalinas do sul do Estado da Bahia. Notas preliminares e estudos da Divisão de Geologia e Mineralogia, Rio de Janeiro, 141:3-11.

Halls, H.C. 1982. The Importance and Potencial of Mafic Dyke Swarms in the Studies of Geodynamics Processes. Geosc. Canadá, 9:145-154.

Halls, H.C. \& Fahrig, W.F. (eds) 1987. Mafic Dyke Swarms. Geol. Assoe. Canada, Special Paper, $34,503 \mathrm{p}$.

Johnson, A.M. \& Pollard, D.D. 1973. Mechanics of growth of some laccolithic intrusions in the Henry Mountains. Utah. I: Field observations, Gilbert's Model, physycal properties and flow of magma. Tectonophysics., 18:260-309.

Karmann, I. 1987. O Grupo Rio Pardo (Proterozóico Médio a Superior): Uma Cobertura Para-PIataformal da Margem Sudeste do Craton do São Francisco. Instituto de Geociências, Universidade de São Paulo, São Paulo, Dissertação de Mestrado, 129p

Lima, M.I.C. de; Fonseca, E.G. da; Oliveira, E.P. de; et al. 1981. Folha SD-24 Salvador. Cap.l Geologia. In: Brasil, Ministério das Minas e Energia. Secretaria Geral. Projeto RADAMBRASIL, 25-192.

Martins, A.A.M. \& Santos, R.A. dos 1993. Ibicarai-Folha SD.24-Y-B-V, Estado da Bahia. Texto explicativo. DNPM-CPRM, 212p, 2 mapas.

McBirney, A.R. \& Murasc, T. 1984. Rheological properlics of magmas. Ann. Rev. Earth Planei. Sel., 12:337-357.

McBirney, A.R. \& Nicolas, A. 1997. The Skaergaard Laycred Series.Part II. Magmatic flow and Dynamic Laycring. Journal of Petrology, 38, 5:569-580.

Morin, D. \& Corriveau, L. 1996. Fragmentation processes and xenolith transpor! in a proterozoic minette dyke, Grenville Province, Quebec. Contrib. Mineral. Petrol., 125:319-331.

Nicolas, A. 1992. Kinetics in magmatic rocks with special reference to gabbros. Journal of Petrology, 33:891-915. Cong. Brás. de Geol., 31, Camboriú-Santa Catarina, 4:2149-2162.

Parker, A.J.; Rickwood, P.C.; Tucker. D.H.(eds.) 1990. Mafic dykes and emplacement mechanisms. A.A. Balkema/ Rotterdam/ Brookfield. Publ. 23, Inter. Geol.Correl. Prog., Project $257, .2{ }^{\text {nd }}$ Inter. Dyke Conf., Adelaide / South Austrália, $506 \mathrm{p}$.

Pedreira, A.J. 1979. Possible evidence of a precambrian continental collision in the Rio Pardo Basin of Eastern Brazil. Geology, 7:445-448.

Philpotts, A.R. \& Asher, P.M. 1994. Magmatic flow-direction indicators in a giantdiabase feeder dyke, Connecticut. Geology, 22:363-366.

Pollard, D.D.; Muller, O.H.; Dockstader, D.R. 1975. The form and growth of fingered sheet intrusions. Geol. Soe. Amer. Bull., 86:351-363.

Reches, Z. 1978. Analysis of faulling in three-dimensional strain field. Tectonophysics., 47:109-129.

Reches, Z. 1988. Evolution of fault patterns in clay experiments. Tectonophysics, 745:141-156.

Renné, P.R.; Onstott, T.C.; D'Agrella Filho, M.S.; Pacca, I.G.; Teixeira, W. $1990 .{ }^{40} \mathrm{Ar} /{ }^{39} \mathrm{Ar}$ dating of 1.0 - 1.1 Ga magnetizations from the São Francisco and Kalahari Cratons: Tectonic implications for Pan-African and Brasiliano Mobile Belts. Earth and Plan. Scien. Letters. 101,2-4:349-366

Rickwood, P.C. 1990. The anatomy of a dyke and the determination of propagation and magma flow. In: Parker, A.J.; Rickwood, P.C. \& Tucker, D.H. (eds.) Mafic Dykes and Emplacement Mechanisms, 81-100.

Rubin, A.M. 1995. Propagation of magma-filled cracks. Ann. Rev. Earth Planei. Sei., 8:287-336.

Sabaté, P. 1996. Estrutura e tectônica do embasamento Arqueano e Proterozóico Inferior do Estado da Bahia. In: Barbosa, J.F.S. \& Dominguez, J.M.L. (eds.) Mapa Geológico do Estado da Bahia. Texto Explicativo., Cap. X, 199-226.

Segall, P. 1984. Formation and growth of extensional fracture sets. Geol. Society ofAmer. Buli., 95:454-462.

Shaw, H.R. 1969. Rheology of basalt in the melting range. Jour. of Petrol, 10:510-535.

Shaw, H.R.; Wright, T.Z.; Peck, D.L.; Okamura, R. 1968. The viscosity of basaltic magma: an analysis of field measurements in Makuopuhi Lava Lake, Hawaii. Amer. Journal of Science, 266:225-264.

Shelley, D. 1985. Determining paleo-flow directions from groundmass fabric in the Lyttelton radial dykes, New Zealand. J. Vole. And Geotherm. Res., 25:69-79.

Smith, R.P. 1987. Dyke emplacement at Spanish Peaks, Colorado. In: Halls, H.C. \& Fahrig,W.F (eds.), Mafic Dyke Swarms. Geol. Assn. Canada, Spec. Paper, 34:47-54.

Silva Filho, M.A.; Mascarenhas, J.F.; Moraes Filho, O.; et al, 1974. Projeto Sul da Bahia Relatório Final. Convénio DNPM/CPRM, Salvador, 15 vols.

Tanner de Oliveira, M.A.F. 1996. Petrografia dos Diques Máficos. In: Corrêa Gomes, L. C; Tanner de Oliveira, M. A. F.; Motta, A. C. \& Cruz, M. J. M.(eds.), Províncias dos Diques Máficos do Estado da Bahia. Mapa, Evolução Temporal e Estágio Atual do Conhecimento, Convénio SICM/SGM/PPPG/UFBA. Cap.III. 49-74.

Teixeira, W.; Kamo, S.L. \& Arcanjo; J.B.A. 1997. U-Pb zircon and baddeleyite age and tectonic Earth Sciences, 10,1:91-98.
Oliveira, E.P.; Lima, M.I.C.; Marques, N.M.G. 1980. Maciço sienítico de Itabuna, Bahia. SBG, intcrpretation of Itabuna alkaline Suite, São Francisco Craton, Brazil. Jour. of South Amer 